\title{
DE POSTMODERNIDAD, NIHILISMO Y POÉTICA. SUJETO, SENTIDO Y EFECTOS RETÓRICOS DE INTERVENCIÓN SOCIAL
}

\author{
Susana DÍAZ \\ Grupo de Investigación del SELITEN@T \\ luxmare@telefonica.net
}

Resumen: Se analiza el nihilismo como desafío epistemológico inherente a la postmodernidad y se muestra el diálogo entre las dos matrices teóricas que, dentro del panorama poético español del último tercio del siglo Xx, han afrontado dicho desafío.

Abstract: This article points out on the analysis of nihilism as an epistemological challenge inherent to Post-modernity by showing and discussing the dialogue the twofold theoretical matrixes wich, within the poetic panorama in the last three decades of Xxth Century Spain, have dealt with that challenge.

Palabras clave: Postmodernidad. Nihilismo. Poética.

Key words: Post-modernity. Nihilism. Poetics. 
Es moneda común caracterizar nuestro actual horizonte de autocomprensión haciendo equivalentes postmodernidad y reconciliación acrítica con lo dado. El debilitamiento de nuestros discursos sobre el mundo -en el sentido que da al término Gianni Vattimo- como consecuencia del rechazo del pensamiento postmoderno a las categorías fuertes (las causas primeras, la evidencia que se impone como verdadera) propias de la metafísica y su historia, han llevado a que sea posible designar nuestra época como el fin de la modernidad. Este estado de cosas, que puede sintetizarse como el fin de los grandes metarrelatos, por utilizar la conocida fórmula de Lyotard, en el plano de la reflexión política se plasma en el rechazo a la idea de proyecto, esa idea que señala el modo de ser característico que marca la cultura de la modernidad en el pensamiento occidental ${ }^{1}$. Precisamente este debate que recusa la postmodernidad como presunto conservadurismo frente a una modernidad crítica y emancipadora constituye, a mi modo de ver, un centro neurálgico de la discusión teórica en el panorama poético español de las últimas tres décadas.

Es evidente que a estas alturas la reflexión en torno a las relaciones modernidad/postmodernidad cuenta con una abundante bibliografía producto de las distintas lecturas cuyo rastro no cabe perseguir aquí. Resulta sin embargo necesario detenerse, siquiera sea de forma muy somera, en el malentendido de fondo que ha marcado los perfiles más generales de dicha reflexión. Ese malentendido reside en hacer de la postmodernidad una noción fundamentalmente histórico-cronológica, evidentemente no tanto porque desde un nivel pragmático la postmodernidad no pueda ser leída en esos términos - lo que a todas luces, en términos historicistas, es perfectamente posible y pertinente- sino porque el hecho de radicar la cuestión de su especificidad en esa significación pragmática implica pensar la condición postmoderna desde la hermenéutica de la modernidad, neutralizando las potencialidades efectivas de aquélla al hacerla funcionar bajo una lógica que le es fundamentalmente ajena. De ello se ocupa con lucidez cristalina Quintín Racionero (1998) en «No después sino distinto. En torno a un debate sobre ciencia moderna y postmoderna», texto al que remito y en el que el primer punto a su-

\footnotetext{
1 «Estos relatos [los metarrelatos que han marcado la modernidad] no son mitos en el sentido de fábulas (incluso el relato cristiano). Es cierto que, igual que los mitos, su finalidad es legitimar las instituciones y las prácticas sociales y políticas, las legislaciones, las éticas, las maneras de pensar. Pero, a diferencia de ellos, estos relatos no buscan la referida legitimidad en un acto originario fundacional, sino en un futuro que se ha de producir, es decir, en una Idea a realizar. Esta Idea (de libertad, de «luz» del socialismo, etc.) posee un valor legitimante porque es universal. Como tal, orienta todas las realidades humanas, da a la modernidad su modo característico: el proyecto, ese proyecto que Habermas considera aún inacabado y que debe ser retomado, renovado» (Lyotard, 1994: 30).
} 
brayar es la dimensión constitutiva de la postmodernidad como noción no histórica sino polémica. Desde la perspectiva que Racionero plantea es esta dimensión controversial y agonística la que con más contundencia señalaría el texto de Lyotard La condición postmoderna, puesto que precisamente la idea de condición se ajusta de antemano al objetivo de deshacer el malentendido de una interpretación histórica: no una época, sino una actitud, una sensibilidad, una cultura cuyo centro propulsor se ubica en la neta impugnación de la Idea tradicional de Historia, entendida ésta como una sucesión cronológica de hechos que se despliegan conforme a principios inmanentes de orden y cuyo conjunto está dotado de sentido. A partir de las tesis de Foucault, Racionero plantea cómo, mientras para esa idea positivista de la historia el problema más importante estriba en determinar los nexos de relación significante entre distintos acontecimientos o situaciones, localizándolos linealmente en torno al eje estructural de un ahora que los articula como antes y después ${ }^{2}$, el argumento de Foucault permite formular ante nosotros las preguntas cruciales: ¿qué valor tiene el que se proponga ese eje? Y ¿qué o quién lo legitima otorgándole un significado propio? ${ }^{3}$. El problema es que concebido ese ahora como una efectuación real de su espacio sólo imaginario, no puede ni caer bajo la responsabilidad de la historia ni ser referencia de su fundamento, y siendo así sólo cabe entenderlo, en rigor, como expresión de una determinada episteme ${ }^{4}$. Se hace entonces necesario concluir, con Foucault, «que no existe la historia, sino series múltiples (a veces consecutivas, a veces superpuestas) de discursos acerca de lo legítimo y en contra de

2 Con su correlato casi inevitable causa/efecto, podríamos añadir además.

3 «Que el punto o trecho de tiempo que debe localizar un tal eje es puramente imaginario, está fuera de duda: expresa ese «ahora», de que antes hablábamos, cuya función, desde el punto de vista del discurso histórico, no consiste sino en introducir una instancia meramente organizativa, capaz de generar una topología de la distribución de los sucesos. En tanto que expresión del «ahora», esta instancia se ofrece, ella también inestable y fronteriza; incluso resultaría contradictoria, si se la quisiera pensar materialmente, puesto que debe concebirse a la vez como estática, a fin de hacer posible el reparto de los sucesos, y como dinámica, a fin de servir de gozne a los respectivos «antes» y «después». No tiene, por tanto, realidad alguna o, dicho de otra forma, no refiere a ningún hecho concreto, habida cuenta de que sobre todos ellos cabe hacer recaer la misma función axial de organizar el orden de la historia. Con todo, que en la óptica del discurso histórico ese trecho de tiempo imaginario no se ofrece vacío ante nuestros ojos, es igualmente indiscutible. Decimos «ahora» (respecto de cualquier corte cronológico elegido), pero inmediatamente entendemos «lo que ahora sucede», «el estado como ahora están las cosas», «la situación que ahora se vive». Lo que constituía una operación formal, una mera configuración topológica, se nos ofrece así como una realidad objetiva, dotada de significado» (Racionero, 1998: 6).

${ }^{4}$ Esto es, como «un sistema de comprensión, una estructura de códigos y prejuicios a cerca del orden, sentido y relevancia de las cosas, que no constituyen la historia, sino que se dan en ella - en el puro transcurrir del tiempo - a título de establecer los mecanismos inconscientes de prescripción de lo válido y de lo inválido, lo forzoso y lo accesorio, lo comprensible y lo incomprensible, en cuyas redes las sociedades fraguan su cohesión y forjan su identidad» (Racionero, 1998: 7). 
lo prohibido, cada una de las cuales aspira a identificarse con la historia puesto que de todas maneras cumple el rol de generar una topología de sus propias reconstrucciones y proyecciones en el tiempo». De esta forma, eso que llamamos historia viene a ser el relato que de sí mismos hacen los discursos de dominación como legitimación de su autoridad y permanencia. De aquí se sigue que tendremos que aceptar que haya tantas historias como discursos de dominación y que la relación de cada una de ellas con respecto de las otras sea de negación y violencia, en tanto que todas compiten por el dominio. El punto decisivo a considerar es que, si bien una vez planteado el problema en estos términos la tarea crítica del pensamiento estribaría en analizar qué relaciones inconscientes mantienen los discursos del saber con respecto del poder, este esquema no es aplicable al relato de la modernidad en la medida en que la episteme moderna se constituye precisamente sobre el reconocimiento de la reflexión como su valor fundamental, de forma que el relato de la modernidad es, él mismo, el relato de la reflexión, ocupando en la continuidad de su desarrollo el control de la historia misma ${ }^{5}$. Desde esta perspectiva, podemos ya establecer que, cuando aquí hablamos de postmodernidad, el prefijo post establece lo esencial de su espacio con respecto a la historia en «un colapso del discurso que estructuraba dicho concepto de historia como parte central del dispositivo integrador del sistema de significaciones de la modernidad» y cuya consecuencia inmediata es hacer posible la liberación de la reflexión en la medida en que con ello «se libera a su vez de su propio relato a la historia misma del pensamiento» (Racionero, 1998: 11). Es justamente en su no-paralización del ahora donde la cultura de la postmodernidad se afirma como lugar de permanente diálogo (en controversia y en convivencia) entre los discursos, prácticas e interpretaciones de que se compone el mundo en que de hecho vivimos y donde, por tanto, reside su especificidad constitutiva como un espacio, y no un tiempo, distinto.

«[...] porque él es la única garantía de que la reflexión retenga siempre los restos adecuados, no otros, de sus ejercicios anteriores y los oriente en una dirección única conforme a un trazo que ha de postularse (en realidad sólo postularse) como perfectivo y continuo. Lo que el relato de la modernidad prevé es el orden y sentido de los episodios de la reflexión, la topología de las reconstrucciones y proyecciones que conforman su historia, la estructura de su ocupación en el tiempo. En la medida en que esta estructura se aplica aquí al control, a la subordinación, no de una episteme singular, sino de todas las epistemes históricas, su condición de relato de los relatos se hace pues, manifiesta: él es la episteme de todas las epistemes. Pero, a decir verdad, que el instrumento de control de tal relato sea la reflexión no tiene por qué significar que él mismo, el relato que históricamente se ha arrogado la propiedad de ese instrumento, deba quedar inmune al control de la reflexión. Puede también querer decir lo contrario. Puede querer decir que el único obstáculo que la reflexión halla para el ejercicio pleno de sus funciones sea su propio relato. O dicho de otra manera: que para liberar el control reflexivo - para hacer posible, en suma, la tarea crítica del pensamiento- es necesario abolir el relato de la modernidad» (Racionero, 1998: 10). 
Este rastro de libertad tiene efectos, asimismo, sobre la categoría de sujeto, al generar la posibilidad de articular una noción no metafísica de sujeto histórico que pueda servir de base a la posibilidad de la acción política. De ello se ocupa otro texto de Quintín Racionero titulado «Sujeto político. Comunidad histórica y nihilismo» (2005). La cuestión puede definirse así: el efecto más inmediato del discurso postmoderno sobre la categoría de sujeto histórico radica en mostrar la nula consistencia de esta categoría al margen de las estructuras discursivas que la reconocen como tal, de forma que el entero programa de la filosofía moderna de la historia entre en suspensión al anularse su referente ontológico. En una somera síntesis, puede decirse que dicho programa obedece a un modelo causal: consiste en concebir el ámbito de las producciones objetivas como un resultado de la acción del hombre, es decir, en tanto efecto confluyente de la racionalidad y la libertad. A su vez, tales producciones se entienden como hitos, episodios fragmentarios y heterogéneos de un mismo y unitario proceso de producción que, también a su vez, no es otro que el del despliegue, en su distensión temporal, de la historia misma. En breve: la filosofía moderna de la historia habla de la historia en la medida en que habla del hombre, y sólo puede hacerlo así.

Resulta ahora necesario hacer una importante precisión para poder poner de manifiesto cómo todo este tejido de relaciones se articulan dentro de lo que Racionero llama una óptica de la espera sobre la que la filosofía moderna de la historia radica su fuerza mayor: su dimensión moral. Se trata exactamente de distinguir entre sujeto como categoría relativa a una función sintáctica y ente como presupuesto que dotaría de contenido semántico a dicha función. Así, si cuando hablamos de sujeto hablamos de una categoría bien determinada, en cambio, cuando hablamos de ente hablamos de un contenido todavía por determinar. Para Racionero es precisamente el problema que introduce esta cláusula temporal y de la que depende la pregunta por cuál deba ser la naturaleza de ese ente que cumple la función de los juicios históricos, lo que constituye el centro neurálgico del programa moderno de la filosofía de la historia ${ }^{6}$.

\footnotetext{
${ }^{6}$ «Enuncia, en efecto, que es lícito esperar que los datos de apariencia fragmentaria y heteróclita de la historia empírica verifiquen la identidad aún en curso de su proceso de producción, puesto que tal identidad no es otra que la identidad, determinada por más que todavía no cumplida, de su sujeto humano. Y digo que es lícito esperar esto, porque la verificación que aquí se pide no requiere apelar a los hechos empíricos mismos; es suficiente con que pueda conformarse - con que se ajuste o no resulte contradictoriaa la interpretación que de ellos hace esa óptica de la espera, de la distensión temporal, en que, a través de los hechos pero más allá de ellos ha de cumplirse en su plenitud el ser del hombre. Es fácil ver que una tal óptica introduce una suerte de escatología laica, secularizada, como última llave de los juicios históricos,
} 
Es justamente en la suspensión de esta óptica de la espera y del modelo causal al que obedece, donde la postmodernidad encuentra la efectividad de su dimensión política. En esta suspensión juega un papel determinante la noción de discurso ${ }^{7}$ y la crítica de Foucault a la idea tradicional de historia sobre la que páginas atrás nos detuvimos. $\mathrm{Si}$, en efecto, la historia del pensamiento no puede entenderse ya, a partir de dicha crítica, como el proceso de sedimentación de la verdad que el concepto fija y la voluntad anima, sino como la memoria del conjunto de juegos lingüístico-pragmáticos en los que la realidad se efectúa de manera plural y contingente bajo circunstancias concretas de la autocomprensión humana, es evidente que las epistemes (esos sistemas estructurados de reglas que articulan los principios reguladores básicos del discurso) «no son el resultado de la racionalidad operando sobre la libertad, ni tienen por motivo el orden de las vivencias subjetivas que conforman el ámbito de lo humano». De ello se deriva que la posición estructural correcta sea aquí exactamente la contraria a la que mantiene el modelo causal de la filosofía moderna de la historia: «es la episteme subyacente, en la medida que rige un discurso, la que provee todos y cada uno de los criterios reguladores de las vivencias; en otras palabras, quien da su lugar, llama e instaura a las ciencias humanas, permitiendo al hombre constituirse como su objeto» ${ }^{8}$. Ahora bien, es precisamente la consciencia de este punto, del hecho de que vivimos en las epistemes, de que ellas son nuestro mundo físico, donde adquiere materialidad lo que Racionero llama el cerco del nihilismo y cuyo horizonte puede resumirse así: puesto que no hay sujeto de la historia, que organice la libertad desde la racionalidad, sino sujetos constituidos en ella por las estructuras del discurso - esto es, no hay una producción de la objetividad sino una constitución de la subjetividad y, por lo mismo, tampoco hay una relación de causa efecto entre el hombre (como sujeto) y sus obras (como objeto)—, entonces toda la racionalidad y toda la libertad se dan dentro del discurso y fuera de él no hay nada. Sin embargo,

los cuales, por ello mismo, adscriben una dimensión moral, axiológica, a su estricto contenido fáctico. Pero esto no constituye una objeción, antes bien, es el factor que da fuerza al programa de la filosofía moderna de la historia. Pues es por relación a esa óptica como cobran valor emancipatorio las referencias a la unidad y la racionalidad de la historia, así como el carácter material y moralmente progresivo de su despliegue, cosas todas que, en definitiva, no hacen sino traducir un cómputo de atributos (y deseos) específicamente humanos» (Racionero, 2005: 30-31).

${ }^{7}$ Esto es, la estructura o sistema de significaciones en virtud del cual se organiza el campo del saber y la experiencia, determinando con ello el específico modo de ser de los objetos que en ese campo aparecen.

${ }^{8}$ Así, el hecho de que la episteme moderna atribuya al hombre el papel de «el que hace su propia historia» significa tan sólo que esa atribución es un elemento inscrito en las reglas del juego de esa misma episteme. 
como muestra en su argumentación, la afirmación de que sólo hay discurso: el todo de las estructuras y sus configuraciones, admite ser pensada de dos maneras distintas. Se trata ahora de analizar, tras asumir la historia como un proceso sin sujeto, la radical apertura de espacios, vale decir, de libertad, que, a través de su consideración del carácter contingente de las estructuras epistémicas, proporciona el discurso de la postmodernidad.

La primera de esas dos aproximaciones a las que acabo de hacer referencia es, para Racionero, la que caracteriza gravemente el estado de cosas de nuestro tiempo y en la que la acción política deviene aparente. Esta posición de pensamiento único es la que prevé la absoluta impensabilidad de cualquier margen más allá del todo y de sus determinaciones: el sistema incluye absolutamente la nada — nada hay fuera de él—. El discurso viene aquí pensado como entidad íntegra. Desde esta perspectiva, no es concebible que haya pérdidas en sus estructuras y, por tanto, que pueda darse el espacio para una producción no previsible de la libertad ${ }^{9}$. Las cosas cambian cuando de una aproximación del Todo unitario y de una nada absolutamente absorbible por el ser, pasamos a otra de los todos parciales en la que dicha absorción no puede darse de manera absoluta. Y esta segunda aproximación es, precisamente, la que reclama para sí el carácter histórico, y por ello, contingente, de las estructuras:

El hecho de que nuestros análisis—genealógicos o arqueológicos—se vean forzados a permanecer siempre en el plano sincrónico, significa que las estructuras sí experimentan pérdidas, que incluyen sólo apropiaciones parciales, que no controlan la totalidad de los elementos posibles y que es de este desajuste de donde procede su transformación y, a veces, su destrucción. [...] En la óptica de las totalidades parciales, la diferencia entre discurso y todo, entre conocimiento y realidad, entre historia y naturaleza y, en definitiva, en-

\footnotetext{
9 «La idea de que la acción política es aparente — de que el sistema sólo admite variaciones tal vez de talante o sensibilidad, pero no de fondo- ha llegado a ser de hecho, consustancial a nuestra percepción política ordinaria. [...] Ahora bien, frente a las extrañas afirmaciones, tan cargadas de convicción como ausentes de certeza, que subyacen a estas actitudes, lo que se impone comprender aquí es que los sucesivos «no» que ellas mismas involucran — «no es realista», «no es racional», «no es posible»— sólo tienen validez si se admite, simultáneamente, que los límites que introducen (y las reglas de que son expresión) agotan la totalidad de las alternativas que pueden pensarse para cada caso; o sea: si se admite que las determinaciones del sistema, que de todos modos nacen de una negación, resultan positivamente necesarias. [...] Con eso que a diario oímos, lo que se nos pide en rigor es que demos por aceptable que un enunciado polémico-negativo (del tipo «no hay otra opción para esto»), que presupone las reglas del sistema, se convierta en un enunciado apodíctico-positivo (del tipo «ahora esto es necesario»), que implica, en cambio, una afirmación de validez absoluta. Pero ¿está legitimada esta metábasis? ¿Es obligatoria esta interpretación positiva de la negatividad?» (Racionero, 2005: 44-45).
} 
tre lo pensado y lo impensado se muestra efectivamente insuperable. [...] No hay modo de salir de esta dificultad, con respecto a la cual sigue siendo válida la objeción general que siempre puede plantearse contra el método analítico. [...] Entre los efectos y las causas, igual que entre los elementos y la estructura, nada hay que pueda distinguirlos; y lo que sabemos de esa causa o de esa estructura, nada es tampoco al margen de los efectos o de los elementos del conjunto. Sin embargo, en las significaciones que estos usos del término «nada» introducen hay ahora una diferencia fundamental. Esta nada, la que se perfila cuando del sueño del todo unitario pasamos a la consideración de los todos parciales, ya no se muestra - ya no puede mostrarse ciertamente- como absorción completa por el ser, sino como vacío: como resto o margen que establece un hiato, una escisión entre el ser y la estructura; entre el hueco que deja el ser y la presencia incompleta del ente que ocupa su lugar (Racionero, 2005: 46-47).

Esta segunda aproximación al nihilismo propuesta por Racionero puede enunciarse así: el sistema incluye absolutamente la nada — fuera de él habita la indeterminación-. Y es en su asunción plena donde se hace posible elaborar una noción no metafísica de sujeto histórico que pueda servir de base efectiva en el campo de la acción política. Es desde esta perspectiva, desde donde la lectura de Hegel propuesta por Racionero puede asumir el hecho de que «nada hay fuera del discurso» no tiene por qué limitarse a decir que la determinación niega la nada, puede también querer decir que fuera del discurso rige la no-determinación ${ }^{10}$. La nada es aquí una ausencia reparable en la medida en que puede ser pensada como consciencia de las desarticulaciones del sistema y, por tanto, como deseo o voluntad de determinación, lo que en términos hegelianos se traduce como libertad. Ahora bien, sólo bajo la forma de una libertad determinada lo racional puede hurtarse a la nada, y es éste el proceso que Hegel identifica con la actividad de la razón ${ }^{11}$. En síntesis, la filosofía hegeliana de la historia se erige sobre la distinción entre un uso objetivante, instrumental de la razón y que es el propio del ámbito histórico de la conciencia, y un uso absoluto de la razón, que no es susceptible de quedar recluido en ninguna configuración determinada y que, por ello mismo, es capaz de establecer un criterio de contrastación respecto de aquel

${ }^{10}$ Como se sabe, el «nada hay fuera del discurso» es también el punto de partida de Hegel: nada hay fuera de esa trama o red identificada con las figuras, (consideradas al margen de su sucesión) del Espíritu Objetivo.

${ }^{11}$ La libertad no puede regir como principio absoluto de determinación, puesto que si así fuese esto llevaría, por un lado, a que la virtud no podría distinguirse del terror y, por otro, a que volveríamos de nuevo a la nada, una nada aún más desgarradora puesto que sólo autosatisfecha en el derrumbamiento de todos los obstáculos a su paso. 
uso objetivante. Ambos usos se retroalimentan mutuamente y es precisamente su funcionamiento conjunto lo que da lugar a la lógica de la historia: la dialéctica. Sin embargo, la dinámica dialéctica del doble juego de la afirmación positiva de la conciencia y la negación superadora de la Razón ha de prever, no sólo para ser posible, sino siquiera concebible, un desideratum de orden previo y distinto a la ejecución de la dialéctica: este desideratum es la confianza en que la Razón puede soportar, absorber siempre, en todos los casos, la cuota de sinrazón, de mal relativo, que contiene cada realización particular de la conciencia para así poder asegurar el proceso de racionalidad creciente de la historia siendo, a través de este criterio de ganancia creciente, como se reconcilia la historia empírica con la historia ideal, esto es, con la historia como sistema. De aquí la dimensión moral que constituye el motor de legitimidad de la filosofía moderna de la historia. Ahora bien, este criterio de ganancia, que en Hegel adopta la forma de progreso y que a juicio de Racionero es, frente a la dialéctica, la clave profunda de la filosofía moderna de la historia, no puede tener ya a la libertad como principio puesto que no puede justificarse ni en la voluntad de determinación ni en ninguna de las realizaciones objetivas de la racionalidad determinante. Emerge como lo que es: una hipótesis inductiva que sólo sería posible mantener si, empíricamente, la sinrazón y el mal particular no desbordan la capacidad de progreso acumulativa de la razón. Y aquí llegamos al punto donde la filosofía de la historia encuentra su límite absoluto: esa capacidad hace tiempo que ha sido refutada con creces por la historia empírica. Casos como el genocidio judío en la Alemania nazi u otros genocidios posteriores demuestran que la ganancia obtenida es de un orden inconmensurable con el mal perpetrado. Sin embargo, lo inconmensurable no ha de entenderse en un sentido moral, sino en un sentido sensu stricto lógico que hace posible describir su espacio en términos de voluntad de poder ${ }^{12}$.

Como se sabe, es Nietzsche quien ha desvelado la esencia del nihilismo al conectar las nociones de realidad indeterminada y voluntad de poder: en la

12 «En el sentido de una completa incoherencia semántica con lo significado por el concepto de Razón, tanto en su uso absoluto, como también (y esto es más característico) en su uso instrumental. Porque, en efecto, para no salir de este último uso [...] viniendo a casos más recientes, y también, de nuevo, sólo en el plano instrumental, ¿qué rendimientos racionales pueden seguirse de la sistematización global de un mundo, que, de extenderse, según se dice pretender, a todas las regiones del planeta, acabaría con algunas de las reservas básicas (hoy conocemos con toda precisión el dato) en apenas cinco años? [...] Pero no hay que dejarse aturdir por la objetividad de estas pasiones; [...] lo que importa comprender es que, si pueden seguir interpretándose - y nada hay que lo impida — conforme al canon explicativo de la libertad determinada, en cambio no son ya descriptibles en términos de racionalidad, sino de estricta e imperiosa voluntad de poder» (Racionero, 2005: 52). 
medida en que relaciona la realidad con la pura resolución de la voluntad, lo que Nietzsche desvela es el significado auténtico de las representaciones de la Razón, y ello de manera que las verdades se transmutan en valores. Puede entonces concluirse que el efecto radical del nihilismo es que, al mismo tiempo que aniquila las representaciones de la Razón, hunde también la idea de que existe una necesidad racional determinada de los valores en quien la voluntad encontraría un criterio seguro para la acción. O sea, lo que la esencia del nihilismo implica es la total suspensión de la idea misma, exacta, que preside el fundamento de legitimidad de la filosofía de la historia.

Esta asunción del nihilismo pone en juego decisivas implicaciones que debemos considerar. La primera de ellas radica en llevar el ser al ámbito que le es propio y que no es otro que el de la libertad. A su vez, esto no indica que la libertad no esté en ningún caso determinada, ni que pueda prescindirse del conjunto de determinaciones que constituyen la memoria de su historicidad; lo que ahora se enuncia es que las determinaciones de la libertad no tienen su origen en ninguna identidad ontológica que convierta el despliegue de la historia en necesario y perfectible (de ahí su carácter de progreso). De esta forma, si lo real se da siempre en la pluralidad de las determinaciones posibles, todas y cada una de las determinaciones de esa realidad responde ahora a una decisión de la voluntad y no a una necesidad. Y ello de tal forma que cada decisión conlleva, necesariamente, la consciencia de que su efectuación, en el mismo movimiento en que limita, pone al descubierto, asimismo, el espacio de la pluralidad ontológica. Se trata, por tanto, de una voluntad de reconocimiento que se manifiesta en una actitud de respeto y cuya misma naturaleza implica que ella misma, como voluntad, puede y debe despegarse de sí todas y cada una de las veces que la atención a sus distintas determinaciones así lo exija ${ }^{13}$. Y es exactamente en este pliegue de la voluntad como despegamiento o distancia de cada una de sus determinaciones libres donde aquélla se muestra, no ya como una función de la libertad, sino como una función del conocimiento, una función de la razón ${ }^{14}$. Asimismo, es en este marco de

13 «Frente a la lógica de la sobredeterminación que el nihilismo traduce en voluntad de poder, en la lógica de la pluralidad el nihilismo se ofrece [...] como voluntad de reconocimiento de todas cuantas posibilidades han quedado o pueden aún quedar abiertas a la ejecución que ella misma voluntad lleva a cabo y por la que esas posibilidades, en tanto que reales, surgen, devienen objetivas, hurtándose a la nada. [...] en el respeto, pues, hacia las diferencias que, en tanto determinadas o susceptibles de determinación, se abren al ejercicio de los proyectos y decisiones que ella misma se pone como voluntad» (Racionero, 2005: 55).

14 «[... al excluir la figura de una razón que necesariamente ha de identificarse con sus producciones, el nihilismo no excluye con ello la capacidad de razonar sus proyectos y decisiones; simplemente convoca una concepción pragmática de la razón, que si, por una parte, restringe el alcance de su validez al campo de lo efectuado en cada apertura de libertad, por otra parte, encuentra en esa apertura misma — en su na- 
asunción de un nihilismo que ha dejado de ser una forma de negación o indeterminación para ser expresión de un rumbo de la voluntad de poder - y en la que el único requisito necesario es que esa voluntad se dé-, donde el discurso de la postmodernidad, lejos de disolver de una manera presuntamente acrítica la noción de sujeto histórico obliga, desde una voluntad de razón basada en una actitud de reconocimiento y respeto a la patencia de la pluralidad de lo real, a repensar el concepto de sujeto histórico bajo la forma de un sujeto dialógico ${ }^{15}$. Llegados a este punto, se hace evidente la radical apertura a la intervención política que, desde el terreno ideológico, plantea la cultura de la postmodernidad así entendida. Ahora bien, la cuestión decisiva que debe ser destacada aquí, cuando se trata de analizar la posición teórica que desde el campo literario posibilita una tal apertura como efecto retórico de intervención social, es ésta: que la posibilidad real de ese sujeto de diálogo no puede de ninguna manera inscribirse en una liberación de la comunicación sino en la exigencia de mostrar la realidad tal y como se hace patente en la experiencia del nihilismo:

O sea, [...] la obligación, pues, no de liberar la comunicación, sino, a la inversa, [...] Porque el problema es éste, en definitiva. La propuesta de una plena liberación de la comunicación sólo puede cumplirse en el vacío, o, al revés, en la impostura de un uso de categorías y conceptos formales que, bajo una apariencia transparente, objetivan en rigor el dominio de su propio discurso. Formas una y otra de nihilismo, la única posibilidad que nos queda es [...] afrontar esos resultados mismos a través de su exhibición explícita, en tanto que de ella pueden seguirse nuevas decisiones, nuevos proyectos de la voluntad racional (Racionero, 2005: 56-57).

En este sentido, una de las cuestiones (si no la cuestión) que, de una u otra forma, ha marcado - la mayor parte de las veces, sin emerger como tal - la práctica totalidad de los debates teóricos sobre la poesía española del último tercio del siglo $\mathrm{xx}$ es la del carácter retóricamente mediado que presenta nuestra aprehensión del mundo y obviarla supone pasar por alto uno de

turaleza común, siempre repetida en su forma y siempre distanciada de sus objetos-el signo, el rasgo hipotéticamente racional que hace conmensurables, y por ende, comunicables todas sus efectuaciones particulares» (Racionero, 2005: 56).

15 «Una voluntad de razón, cuyas determinaciones no se guían por la realización de la identidad necesaria sino por el reconocimiento y respeto de las diferencias existentes, es — sólo en realidad es— un sujeto de diálogo: la expresión, como he dicho, de una perspectiva hipotéticamente racional, cuyo ejercicio se sabe de una naturaleza pragmática y cuyo horizonte implica, por ello mismo, la aceptación de la pluralidad de todas las otras determinaciones posibles, tanto en lo que se refiere a sus contenidos semánticos como a sus propias reglas» (Racionero, 2005: 56). 
los puntos neurálgicos que han marcado la entera reflexión filosófica occidental desde el siglo XIX hasta nuestros días ${ }^{16}$. Con respecto al ámbito poético esta cuestión comporta poner sobre la mesa las distintas formas de intervención que la palabra poética desarrolla en el terreno ideológico. Como se sabe, este debate se viene sosteniendo entre nosotros desde dos posiciones epistemológicas muy marcadas que, grosso modo, podríamos enunciar así: de un lado, la que hace de ese carácter mediado una restricción que impide avanzar y cuyo reclamo de realismo se articula desde la premisa de que es necesario olvidarse de la mediación y restablecer la identidad entre realidad y representación en aras de una mayor comunicabilidad; de otro, aquella que establece esa mediación como punto de partida desde el que problematizar el propio tejido discursivo para crear nuevas configuraciones de la experiencia. Dos poetas vinculados a la creación de espacios de resistencia desde la izquierda política han encabezado esta discusión teórica que, sin duda, ha marcado y continúa marcando el diálogo intergeneracional de nuestra poesía más reciente. Estos dos poetas son Luis García Montero y Jenaro Talens. Acabo de decir encabezado y no protagonizado. El debate convoca a toda la comunidad poética y son muchos los matices de las diferentes propuestas pero, a la vez, no es menos cierto que estas dos firmas son las que han dedicado una específica atención al problema y que bajo su rúbrica pueden señalarse las dos matrices teóricas puestas sistemáticamente en juego dentro de ese panorama general. Desde la perspectiva de Luis García Montero, es en la vuelta a la figuración del realismo para la defensa de un proyecto de vida en común donde se halla el camino adecuado de intervención en los debates de la postmodernidad:

Esto implica una lectura ideológica de los simulacros. Podemos denunciarlos en nombre del vacío, para dejarle las manos libres al poder convertido en ángel guardián de la Nada; o podemos reivindicar, ya que todo es simulacro [sic] el derecho de inventarnos el simulacro que más nos interese. Por ejemplo, uno que llegue a tener otra vez el valor de la representación, de una nueva representación. [...] Hay que volver a la representación, a la figuración, si

16 «Nietzsche nos enseñó a dudar de la fundamentación de la verdad en la autocerteza de la conciencia propia. Freud nos hizo conocer los admirables descubrimientos científicos que tomaron en serio esta duda, y hemos aprendido de la crítica radical de Heidegger al concepto de conciencia a ver los prejuicios conceptuales que proceden de la filosofía griega del logos y que en el giro moderno llevaron a primer plano el concepto de sujeto. Todo esto confiere la primacía a la «lingüisticidad» de nuestra experiencia del mundo. El mundo intermedio del lenguaje aparece frente a las ilusiones de la autoconciencia y frente a la ingenuidad de un concepto positivista de los hechos como la verdadera dimensión de la realidad» (Gadamer, 2002: 327). 
De POSTMOdERnidad, NIHILISMO Y POÉTICA. SUJETO, SENTIDO...

queremos seguir defendiendo un proyecto de vida en común. [...] Por eso hay un alto valor ideológico en la poesía que construye un sujeto no esencial, y apuesta más por la conciencia que por la identidad, o en todo caso por una identidad consciente de sus raíces históricas y de su voluntad reguladora. $\mathrm{Pa}$ labra poética figurativa en medio de los procesos de liquidación de la conciencia individual (García Montero, 2002: 26-27).

Estas palabras de García Montero se fundamentan en tres nociones sobre cuyo uso y ambigua formulación en su razonamiento conviene detenerse. La primera es la noción de simulacro. La segunda es la noción de postmodernidad. La tercera es la noción de realismo.

Por lo que respecta a la primera, es necesario subrayar que la noción de simulacro no niega el valor realista o no realista de la representación, sino que cuestiona el concepto mismo de representación. Dicho cuestionamiento no se refiere tanto al carácter figurativo o no figurativo de la representación cuanto a la disolución de la lógica de lectura que la noción misma de representación ha implicado desde Descartes. Así, en la lógica representacional propia del discurso de la modernidad es siempre la noción de un fuera de el discurso lo que garantiza la falsación (en sentido popperiano, esto es, la veracidad o no veracidad de los enunciados se fundamenta en su adecuación o no adecuación respectivamente de un mundo referencial al que el discurso remitiría) de este último. De ahí que la noción de copia sea separable - y secundaria con respecto a él- de la de original. Lo que el simulacro aporta como novedad, no es tanto la desaparición de cualquier tipo de representación, cuanto a) la posibilidad de elaborar copias sin original y b) la posibilidad de leer la verosimilitud del original por su adecuación a la copia y no al revés. Las implicaciones ideológicas de esta inversión no pertenecen por ello al ámbito ni de los objetos, ni del mundo, sino, al de los modos de leer y/o ver el discurso que establece la relación entre aquellos dos. Esto hace, por ejemplo, que se produzca socialmente algo tan aberrante como lo que sigue: no es que un hecho sea verdadero y, por eso, aparezca en televisión (por ejemplo en un telediario) sino que es el hecho mismo de aparecer en televisión lo que lo convierte, en tanto efecto social de sentido, en verdadero. Esto quiere decir que desde la perspectiva de un lector espectador educado en la lógica del simulacro a que vengo aludiendo - considerando como tal la surgida en el último tercio del siglo Xx, coincidiendo con la llamada condición postmoderna-, para que una noticia sobre la guerra, por ejemplo la del Golfo de 1991, fuese verdadera tenía que ser previa y fundamentalmente verosímil y puesto que los modos de representación en los que ese lector/espectador ha sido educado se corresponden con la puesta en escena del cine clásico (y de 
su hija natural, la televisión), una imagen era más verdadera cuanto más se acercaba en tanto imagen a la puesta en escena del cine bélico. No es casual, por ello, que tanto en esa guerra como en la siguiente, el ejército norteamericano pidiese la dirección y asesoramiento de directores artísticos de Hollywood (Carmona, 1991; Talens, 1994, 2000).

Epistemológicamente hablando, pues, lo que la noción de simulacro pone sobre la mesa es que el problema no radica en los modos de escribir, sino en los modos de leer. Si la veracidad de un discurso se mide por su adecuación a unas reglas sintácticas de composición imaginariamente asumidas como naturales, es obvio que reflexionar sobre las formas retóricas que están en la base de dichos modos es una forma de desestructurar el carácter ideológico que lo constituye. Decir, como hace García Montero en el texto citado más arriba «ya que todo es simulacro podemos reivindicar el derecho de inventarnos el simulacro que más nos interese», significa, ni más ni menos, prescindir voluntariamente del problema epistemológico y político de fondo.

La segunda noción puesta en juego es la de postmodernidad. Como se vio por extenso páginas atrás, el post no implica un después sino un distinto, implicación de la que García Montero nuevamente prefiere prescindir ${ }^{17}$. Su voluntad de recuperar como forma de intervención en el debate postmoderno la noción de representación que caracteriza la modernidad, asimilando dicha noción a la de simulacro, le lleva a obviar o, lo que es lo mismo, a querer neutralizar las implicaciones que pone en juego el novum que, con respecto a la noción de sujeto, supone el discurso de la postmodernidad.

En este orden de cosas cabe, a partir de la anterior cita de García Montero, preguntarse con Talens (2005: 133), en virtud de qué extraño poder la

${ }^{17}$ Esta concepción de la postmodernidad como un después y no como un distinto es algo de lo que García Montero nunca ha hecho misterio: «Cuando se habla de postmodernidad, muchas veces lo único que se hace es tomar conciencia de esa crisis perpetua de la modernidad. Eso tiene dos lecturas: renunciar - y hay mil maneras de renunciar: desde el cinismo hasta la pureza de no querer mezclarse con la historia- o intentar recuperar el proyecto emancipador de la modernidad. A mí la postmodernidad que me interesa es la que quiere darle una segunda oportunidad a la Ilustración. Para explicar mi poesía y mi posición ideológica siempre digo que estamos acostumbrados a leer los valores de la Ilustración con los ojos del Romanticismo, resaltando sus contradicciones. Y creo que ahora deberíamos releer el Romanticismo con ojos ilustrados» (García Montero, 2004: 2-3. Cursivas mías); o también: «[...] Hay quien piensa que el fracaso de la Modernidad obliga a buscar un ámbito de autonomía estética que se desentienda del diálogo con los demás y con la Historia, un ámbito fundado en la ruptura del lenguaje, el irracionalismo y la negación. A mí me ha interesado volver a la Modernidad, y no porque creo que su mandato se ha cumplido perfectamente, sino porque necesito discutir públicamente sus errores, los caminos equivocados, las renuncias. Más que quemar los libros, deseo volver a ordenar nuestra biblioteca» (García Montero, 2000: 103. Cursivas mías). 
apriorística consciencia de la máscara pessoana que define al poeta como fingidor o la exposición de tal consciencia como desideratum inicial, eliminaría como por ensalmo los (posibles) efectos perversos del sentido de la escritura, desplazando, en cualquier caso, el valor de una práctica al terreno individualizado de la consciencia del escritor que, de esta forma, y aun sin asumirlo claramente, vuelve a situarse como propietario privado del sentido de lo que avala socialmente con su firma. Con todo, esta pregunta no formula más que una parte, aunque una parte muy importante, del problema a plantear ya que, como bien señala Talens, ese efecto de lectura es uno de los efectos posibles y, por tanto, no por más lógico o inmediato resulta completamente excluyente de otros efectos distintos. Las cosas cambian cuando situamos el centro de nuestra reflexión en el hecho de que ese sujeto no esencial que reclama la apuesta teórica de García Montero resulta ser el punto de articulación de un completo programa de puesta en orden de lo visible cuyo reclamo de lo figurativo se establecería, hoy por hoy, como única salida válida para una escritura verdaderamente consciente de su compromiso con la comunidad. Es entonces cuando ese efecto de lectura al que antes me referí deviene excluyente en tanto que es el efecto buscado y, lo que a mi juicio resulta más grave desde un punto de vista ideológico, es buscado en función de sus dimensiones terapéuticas dentro de una política de la lectura supuestamente comprometida con los males que acechan a la comunidad. Al otro lado quedaría el terreno de la experimentación que viene homologado, en virtud de su filiación vanguardista, a una renuncia a ese compromiso:

Mantener el deseo vanguardista de intervención histórica supone, hoy, desde nuestra perspectiva, un cuestionamiento de las vanguardias. [...] Buena parte de la vanguardia alardeó una y otra vez de la destrucción del sujeto tradicional como la mejor forma de mantenerlo vivo: Los mecanismos de esencialización, de desacralización expresiva, que animaron los planteamientos vanguardistas, como una radicalización de la crisis romántica, están suficientemente estudiados y no son muy contrarios al paradigma lingüístico de la literariedad. Sólo se diferencian al elegir las coordenadas de la esencialización, porque unos eligen al individuo que escribe y otros al texto. Otra opción es la del vacío, la toma de conciencia de la nada. ¿Pero qué hacer entonces? Sí, qué hacer, porque también aquí hay diversos caminos. Existe una herencia vanguardista que optó por la materialidad de un lenguaje que insistiera en la nada, en el recuerdo continuo de la desarticulación del sujeto, en la denuncia práctica del carácter fantasmal de la realidad, de su falta de valores estables. El protagonista de esta lírica es el sujeto vacío. Pero ocurre que este tipo de sujeto sólo sirve como metáfora, y es efectivo cuando se limita a recordarnos la no esencia, las intervenciones interesadas de la rea- 
lidad. Objetivamente, sin embargo, ni existe la nada, ni existe el vacío, porque más que con un hueco nos encontramos siempre con la elaboración ideológica de un hueco, a través de la pertinencia de una determinada visión de la realidad. Aunque no sea esencial, siempre hay un sujeto elaborado históricamente, y las insistencias en las desarticulaciones de la nada suelen imponer en el fondo una vuelta a la esencialización, por mucho que se cubran con la piel del vacío (García Montero, 2002: 24-25).

Ignoro, ante la falta de reenvíos bibliográficos, si la alusión de García Montero a la materialidad de una escritura que insistiera en la nada remite a la poética de José Ángel Valente (a partir del trabajo sobre la misma de Miguel Mas, 1986) o si la referencia al sujeto vacío es una llamada al ensayo del mismo título de Jenaro Talens (2000). Como más tarde intentaré mostrar, en cualquier caso resultaría errónea la identificación de ambas propuestas en un mismo espacio teórico, puesto que obedecen a estrategias radicalmente distintas. En lo que quisiera incidir ahora es en esa misma llamada al orden, al deseo de unidad, de identidad, en definitiva de popularidad (en el sentido de encontrar un público) que, como ya supo ver JeanFrançois Lyotard en —un no tan lejano, a efectos de nuestra reflexión1985, puede detectarse en todas las invitaciones multiformes que incitan a suspender la experimentación artística y que se hace patente en las palabras de García Montero: se hace necesario que los escritores vuelvan al seno de la comunidad o, al menos, si se juzga que la comunidad está enferma, darles la responsabilidad de curarla. Cuando Lyotard analiza en qué consistió el desafío de la fotografía y el cine con respecto al realismo pictórico y narrativo, señala la capacidad de aquellos de realizar mejor, más rápidamente y con una difusión cien veces mayor la tarea que el academicismo reservaba al arte realista: preservar a las conciencias de la duda. En este orden de cosas, la fotografía y el cine deben imponerse sobre la pintura cuando de lo que se trata es, como en el caso que nos ocupa, de estabilizar el referente ${ }^{18}$. Precisamente Laura Scarano (2004a, 2004b) viene a ilustrar este punto cuando establece la especificidad y el sentido de la propuesta poética de García Montero no en los términos de una representación del sujeto cuya verdad se enuncia como un previo empírico, sino de aquélla en la que esa

\footnotetext{
$18 \ll[\ldots]$ de ordenarlo respecto de un punto de vista que lo dote de un sentido reconocible, de repetir la sintaxis y el léxico que permiten al destinatario descifrar rápidamente las imágenes y las secuencias y, por lo tanto, llegar sin problemas a la conciencia de su propia identidad al mismo tiempo que a la del asentimiento que recibe, de esta manera, por parte de los demás, ya que estas estructuras de imágenes y de secuencias forman un código de comunicación entre todos. De este modo se multiplican los efectos de realidad o, si se prefiere, las fantasías del realismo» (Lyotard, 1985: 15-16).
} 
verdad viene enunciada «como una invención destinada a generar efectos de verdad en términos de reconocimiento o de consenso social». De lo que se trata, como bien apunta Scarano, es, por tanto, de ofrecer la imagen modélica de un sujeto, de un hombre, que es ya todos los hombres y que se constituye como el patrón orientador para la invención de un personaje creíble (Scarano, 2004a: 221). Emergen entonces los fundamentos de ese programa de puesta en orden de lo visible al que aludí antes. Su espacio supone decidir ignorar de plano el problema del lenguaje como mediación tanto al identificar realismo y representación (Talens, 2005: 132) dentro de una noción de arte como documento, como al eliminar de un plumazo el problema de la subjetividad como construcción discursiva.

Entramos así en el último de los tres puntos a tratar: la noción de realismo. Y aquí llegamos al nudo gordiano de la cuestión: si hablar de una ética de la escritura es hablar de una ética de los modos retóricos de intervención social, la reflexión teórica de García Montero establece, desde esos dos postulados de fondo señalados por Talens, la necesidad de defender una retórica de la transparencia destinada a obviar el que una tal ética constituye la puesta en escena de la dependencia entre juegos de verdad y estructuras de poder (puesto que no hay relaciones comunicativas sino relaciones de poder $\mathrm{y}$, por ello, enfrentarse al discurso es enfrentarse a la realidad social que aquel sintomatiza y conforma). Algo que, como vuelve a recordarnos Talens a través de las palabras de Foucault, no supone ni más ni menos que la disolución de lo político en esa (im)posible transparencia:

La idea de que podría darse una situación de comunicación que fuese tal que los juegos de verdad pudiesen circular en ella sin obstáculos, sin coacciones $y$ sin efectos coercitivos, parece pertenecer al orden de la utopía. Y ello significa no ver que las relaciones de poder no son en sí mismas algo malo, algo de lo que es necesario liberarse. Pienso que no puede existir ninguna sociedad sin relaciones de poder, si se entienden como las estrategias mediante las cuales los individuos tratan de conducir, de determinar, la conducta de los otros. El problema no consiste por tanto en intentar disolverlas en la utopía de una comunicación perfectamente transparente, sino de procurarse las reglas de derecho, las técnicas de gestión y también la moral, el ethos, la práctica de sí, que permitirían jugar, en esos juegos de poder, con el mínimo posible de dominación (Foucault: 2002. Cfr. Talens, 2005: 143-144).

De ello deriva el que García Montero defina en términos de una ética de la renuncia el espacio teórico de aquellas poéticas que asumen la puesta en escena de la dependencia entre juegos de verdad y estructuras de poder como 
una de sus dimensiones esencialmente constitutivas. La denuncia de los mecanismos que permiten preservar a las conciencias de la duda se asimila así a una renuncia. Y esto, habida cuenta de los tiempos que corren, puede ser todo menos una invitación a la resistencia desde la que poder procurarnos el ethos, la práctica de nosotros mismos, que nos permitan jugar la partida de los juegos de poder con el mínimo posible de dominación. Es precisamente en esa invitación a la resistencia donde encuentra su rasgo mayor una concepción de la poesía como pensamiento del desorden de lo visible cuya praxis, al jugar la partida desde la necesidad de enfrentarse al discurso en su propio terreno, esto es, mostrando la dependencia entre juegos de verdad y estructuras de poder, para así hacer efectiva la apertura de un espacio discursivo de intervención y de cambio, ha de emerger necesariamente como una reflexión sobre el estatuto del lenguaje poético y materializarse en una voluntad de experimentación.

A la hora de abordar esta cuestión es útil seguir el rastro que propone Jean-François Lyotard cuando sitúa la fuente del arte moderno y la lógica de los axiomas de las vanguardias en la estética kantiana de lo sublime (Lyotard, 1985: 19-26). Ello nos permitirá detectar el sustrato desde el que emerge, con toda radicalidad, ese pensamiento del desorden, como distintas inflexiones en su formulación. Resumo a continuación sus planteamientos.

En la filosofía kantiana el sentimiento de lo sublime vendría a ser una afección fuerte y equívoca, contradictoria: el placer procede de la pena. En la tradición de la filosofía del sujeto que se remonta a San Agustín y Descartes y que Kant no terminó de cuestionar, este sentimiento se desarrolla como un conflicto entre las facultades de un sujeto: entre la facultad de concebir una cosa y la facultad de presentar una cosa. Para la filosofía kantiana hay conocimiento si, en principio, el enunciado es inteligible y, si, acto seguido, se pueden establecer ciertos casos de la experiencia que se correspondan con éste. Hay belleza si, en ocasión del caso (la obra artística), dado inicialmente por la sensibilidad sin ninguna determinación conceptual, el sentimiento de placer es independiente de cualquier interés que provoque que esta obra suscite hacia ella un consenso universal de principio. El hecho de que el gusto atestigüe que puede experimentarse en el modo del placer un acuerdo no determinado o regulado, da lugar al juicio reflexivo kantiano entre la capacidad de concebir y la capacidad de presentar un objeto correspondiente al concepto. Lo sublime se dará, por el contrario, cuando la imaginación fracase y no consiga la presentación de un objeto que, aunque sólo sea en principio, pueda establecerse de acuerdo con un concepto. Por ejemplo, dice Lyotard, tenemos la Idea del mundo (la totalidad de lo que es) pero no tenemos la ca- 
pacidad de mostrar un ejemplo de ella. De esta forma estas ideas no nos dan a conocer nada de la realidad (la experiencia), ya que prohíben el libre acuerdo de las facultades que produce el sentimiento de lo bello, impidiendo la formación y la estabilización del gusto. Por consiguiente, puede decirse de ellas que son (im)presentables.

Lyotard llama moderno al arte que consagra su técnica a presentar qué hay de impresentable (in-presentable): «hacer ver que hay algo que se puede concebir y que no se puede ver ni hacer ver» y explica cómo la propia filosofía kantiana nos dicta la dirección a seguir a la hora de responder a la pregunta ¿pero cómo hacer ver que hay algo que no puede ser visto? cuando establece su análisis tanto en términos de lo informe, de la ausencia de forma (en términos, en definitiva, de un índice de lo impresentable), como cuando radica la posibilidad de esa presentación en una presentación negativa: así la abstracción vacía que experimentaría la imaginación en su búsqueda de una presentación de lo infinito (otro impresentable) sería ella misma (esa abstracción) una presentación del infinito, su presentación negativa.

Por último, y recogiendo con ello un hilo que antes dejé suelto, si se traslada esta perspectiva al problema del estatuto del lenguaje poético, pueden empezar a introducirse matizaciones, a mi juicio decisivas, sobre dos de las aproximaciones teóricas que con respecto a tal problema han marcado el panorama de nuestra poesía más reciente. Me refiero a las poéticas de José Ángel Valente y Jenaro Talens. No puedo detenerme ahora en una lectura pormenorizada de la específica formulación valentiana poesía es conocimiento y que en otro lugar (Díaz, 2004) ya analicé. Me interesa ahora rescatar el resultado al que dicha afirmación aboca y que no es otro que el de eliminar la condición dialógica del poema al hacer de la poesía el lugar de manifestación del Ser. Esto supone, ni más ni menos, que a través de la condición de verdad que satisface (poesía es conocimiento), el poema deje de configurarse como propuesta de producción de sentido para convertirse en el lugar de una revelación. De ahí que en él sea necesario plantear en primer plano el carácter inconmensurable de la realidad a expresar en relación con el concepto que la expresa y también de que, se quiera o no, el estatuto de la palabra poética siga siendo entonces el de un simple medium comunicativo. En la poética valentiana este esquema se materializa bajo la forma de una metafísica negativa en la que la conciencia queda fuera de juego como centro privilegiado que controla el sentido (el sujeto queda destronado de la enunciación, la escritura se impersonaliza), pero a cambio de establecer una nueva ilusión, a saber, la de la personificación del lenguaje poético como palabra del Ser. Siendo la realidad del Ser inconmensurable en relación con su con- 
ceptualización sólo será posible decirla negativamente, como silencio - $\mathrm{y}$ de ahí la archiconocida poética de Valente: arte de la composición del silencio-. En este sentido, las conexiones de la poética valentiana con la tradición mística española y oriental son todo menos gratuitas.

La reflexión de Talens sobre el estatuto del lenguaje poético obedece a una estrategia completamente distinta. En la lectura de Lyotard sobre el sublime kantiano encontramos formulado su espacio como la inflexión decisiva que marca el lugar postmoderno, esto es, como aquello que alega lo impresentable en lo moderno y en la presentación misma negándose al consenso de un gusto que permitiría experimentar en común la nostalgia de lo imposible:

Un artista, un escritor postmoderno, están en la situación de un filósofo: el texto que escriben, la obra que llevan a cabo, en principio, no están gobernados por reglas ya establecidas, y no pueden ser juzgados por medio de un juicio determinante, por la aplicación a ese texto, a esa obra, de categorías conocidas. Estas reglas y estas categorías son lo que la obra o el texto investigan. El artista y el escritor trabajan sin reglas y para establecer las reglas de aquello que habrá sido hecho. De ahí que la obra y el texto tengan las propiedades del acontecimiento; de ahí también que lleguen demasiado tarde para su autor, o, lo que viene a ser lo mismo, que su puesta en obra comience siempre demasiado pronto. Postmoderno será comprender según la paradoja del futuro (post) anterior (modo) (Lyotard, 1985: 25).

A mi juicio es la imposibilidad misma de experimentar ya esa nostalgia por lo impresentable la que orienta la lectura de Talens cuando, al ocuparse de las fantasías del realismo (que sigue soñando con un acceso directo a las cosas mismas y con las posibilidad de su directa manifestación en tanto representables), señala el valor fundamentalmente positivo al que nos aboca el límite postulado por la filosofía kantiana. Maurizio Ferraris (1986: 50-60) ha perseguido ese rastro del límite kantiano en una específica tradición literaria y filosófica: aquella en que la escritura, partiendo de la ecuación entre el libro y el mundo, asume todas las características de lo que —en la perspectiva de la Nouvelle Critique y, en el plano filosófico, de la gramatología de Derrida-, es la écriture. En efecto, tal y como señala Ferraris, con Kant la filosofía pierde su propio valor heurístico y fundacional frente a las pretensiones cognoscitivas de la ciencia. Con ello, continúa Ferraris, se pierde la esperanza en la posibilidad de una cosmología racional y es precisamente este punto, el de la imposibilidad de definir el mundo como un objeto concreto, la premisa para hacer del libro, como contenedor de todos los sentidos posibles, el 
analogon del mundo mismo. Así, si el libro es el mundo, la escritura no debe confrontarse con un mundo de referentes exteriores y termina por homologarse a la pintura. En este sentido, las elaboraciones tipográficas de la poesía mallarmeana o las teorías de Valéry sobre la pintura, cuya razón de ser consiste en hacernos conscientes de la ausencia de su objeto, nos conducen a un territorio que la gramatología nos ha hecho familiar: el de la grammè como huella de una ausencia. La écriture adquiere una neta dimensión ideogramática, como grafema o significante y es de esta raíz de donde parte la entera crítica derrideana a la jerarquía platónica de un significante sensible que reenvía a, y al que subyace, un significado ideal.

Ahora bien, hay que empezar a realizar aquí algunas decisivas puntualizaciones teóricas. En primer lugar, la de que este concepto de écriture extraído de la ecuación libro = mundo se transforma, en Derrida, en la hipótesis de un valor autoreferencial de la grammé (la cual reenvía a sí misma y alude a un mundo de referentes de los cuales es huella). El segundo punto a considerar es que este desplazamiento en el estatuto del signo constituye una específica objeción a la tesis de Husserl de una conciencia anterior al lenguaje, de un mundo de la vida, de las cuales la palabra y más aun la escritura serían meras representaciones. La cuestión de la escritura adquiere así en Derrida una dimensión ontológica en la que se conjugan la línea mallarmeana a la que antes se aludió y la tradición onto-teológica del olvido del ser en Heidegger. Como se sabe, el olvido del ser constituye en la filosofía heideggeriana la característica fundamental del pensamiento metafísico - la estructura básica del pensamiento occidental desde Platón a Nietzsche-, que se centra en lo presente y manifiesto, esto es, en el ente y sus estructuras, y no atiende al fondo — el ser como iluminación- que hace posible que el ente aparezca. En este sentido, Ferraris señala cómo el concepto mallarmeano del libro y el del ser heideggeriano corresponderían a una misma exigencia conceptual: la de pensar el ser como algo que no se presenta inmediatamente sino, por el contrario, como huella o diferencia. Si para Heidegger el olvido del ser consiste en su poner en presencia, esto es, en presentarlo como ente, la escritura para Derrida es aquello que en su presentación manifiesta una ausencia, la de la voz viviente de la que lo escrito viene considerada una traducción, o, lo que es lo mismo, del referente del que se supone que el signo gráfico sea la huella. En la crítica que Derrida hace a la reflexión heideggeriana, nos situamos exactamente en el punto al que buscaba dirigirme al marcar las diferencias entre los desarrollos de Valente y Talens con respecto al estatuto del lenguaje poético. Para Ferraris, es precisamente en el hecho de transferir a la écriture las características presenciales, 
de contacto inmediato con el mundo, que la tradición metafísica atribuye a la palabra, donde se recupera por entero esa misma tradición. Es esta la cuestión que Derrida reprocha a Heidegger a propósito de sus tesis en El origen de la obra de arte y excluye que se pueda decir la verdad sobre la pintura, $o$ que la pintura pueda decir la verdad («Es el cuadro que ha hablado», escribe Heidegger como conclusión a su análisis de un cuadro de Van Gogh). En efecto, Derrida reprocha a Heidegger el haber inscrito así su propia reflexión en la metafísica pensando el lenguaje como un medio destinado a hacer presente el ser y transformarlo en un ente cuando, más bien, sostendrá Derrida, la verdad es constitutivamente en pintura - esto es, desde su perspectiva, en la écriture - una huella, aquello que es capaz de hacernos conscientes de la ausencia de su objeto.

A mi juicio, es desde esta perspectiva desde donde se hace patente la valencia netamente metafísica que atraviesa la entera poética valentiana, al concebir el estatuto del lenguaje poético como lugar de manifestación del ser, esto es, como lugar donde el ser se pone en presencia. Es desde esta óptica, también, desde donde cobra pleno sentido la estrecha relación que la poética de Valente mantiene con la tradición mística española, y más en concreto, con la obra de San Juan de la Cruz ${ }^{19}$, así como desde donde se hace evidente el calco del esquema valentiano sobre la iluminación (Lichtung) heideggeriana. Como ha definido Ramón Rodríguez (1994) el término iluminación en Heidegger equivale a ser en múltiples contextos y designa el espacio o ámbito de sentido a partir del cual todo ente resulta iluminado, se muestra o aparece, pero de forma que en su acción iluminante él mismo se retrae u oculta. Se trata por tanto de la verdad ontológica o del ser. La elaboración del concepto de verdad poética que Talens lleva a cabo se basa, en cambio, en otro presupuesto. A saber: la consciencia de que esa verdad carece de objeto. El poema se configura rigurosamente como propuesta de producción de sentido $^{20}$. La autorreferencialidad del lenguaje pasa así a ser el eje de su re-

19 «Palabra inicial o antepalabra, que no significa aún porque no es de su naturaleza el significar sino el manifestarse. Tal es el lugar de lo poético. Pues la palabra poética es la que desinstrumentaliza el lenguaje para hacerlo lugar de la manifestación. [...]» (Valente, 1991: 63-64).

${ }^{20}$ De aquí la diferente concepción del silencio en Talens: «Si el lenguaje es un sistema de fórmulas convencionales, aceptar su institucionalización es aceptar mentir al utilizar para construir verdades elementos que no la pueden ni siquiera transmitir, al no tener tampoco existencia fuera de ellos. Queda como alternativa callarse. Pero callarse sólo es la inversión del hecho de hablar. No hay alternativa, pues, en el mutismo, sino en el silencio. No ocurre como en el discurso místico, que, al rebasar el lenguaje como algo insuficiente, se resuelve en un silencio entendido como serenidad. Lo que hay es una conciencia que quiere liberarse de los signos. El silencio no es, pues, una salida que ya estuviera ahí, prevista como alternativa de respuesta, sino una meta difícil de alcanzar, a la que conduce un camino que previamente hay que construir» (Talens, 1979: 49. Cursiva mía). 
flexión y el lugar donde se inscribe la idea de mediación retórica como espacio teórico político de intervención y libertad:

El argumento central de su reflexión [en Kant] es que la verdadera objetividad del conocimiento no está fundada y asegurada en la libre espontaneidad del espíritu, sino en la imposibilidad del conocimiento de la «cosa en sí». Por eso, el corte que separa el conocimiento de las «cosas en sí» no es más que la expresión de que aquél ha encontrado su fundamentación más firme en sí mismo y no en la cosa en sí. Sólo una vez acotado el terreno se abre realmente la posibilidad de jugar en él. Puesto que todo intento de trascender simplemente el campo de la forma está condenado al fracaso, se debe recorrer íntegramente ese campo, y no tocarlo sólo aquí y allá. Si el pensamiento no puede captar directamente lo infinito, debe entonces recorrer lo finito en todas las direcciones (Talens, 2005: 134-135. La redonda es mía) ${ }^{21}$.

Tal y como he analizado por extenso en otro lugar (Díaz, 2006) para Talens, es en la poesía donde se cuestiona la idea de una verdad como adecuación y, por tanto, la quiebra de la teoría representativa, en la medida en que el lenguaje poético es la forma simbólica más puramente simbólica, más autónoma y más libre. De esta forma, la aproximación a las tesis de Heidegger (la obra abre un mundo) y de Gadamer (arte como construcción permanente del mundo) se hacen desde una estrategia en la que el Sentido se da por liberado y manifiestamente superficial.

\section{REFERENCIAS BIBLIOGRÁFICAS}

Carmona, R. (1991). Cómo se comenta un texto fílmico. Madrid: Cátedra.

CASsirer, E. (1973). Filosofía de las formas simbólicas. vol. III. México: FCE.

- (1975). Esencia y efecto del concepto de símbolo. México: FCE.

DíAz, S. (2004). (Per)versiones y convergencias. Madrid: Biblioteca Nueva.

- (2006). El desorden de lo visible. Introducción a la poética de Jenaro Talens. Madrid: Biblioteca Nueva.

Foucault, M. (2002). La hermenéutica del sujeto. Buenos Aires: Fondo de Cultura Económica.

${ }^{21}$ Véase Cassirer (1973: 56; 1975: 171y ss.). 
Gadamer, H.-G. (2002). Verdad y método II. Salamanca: Sígueme.

García Montero, L. (2000). «El oficio como ética». En Poesía histórica y (auto)biográfica, José Romera Castillo y Francisco Gutiérrez Carbajo (eds.), 87-103. Madrid: Visor Libros.

- (2002). Poesía, cuartel de invierno. Barcelona: Seix-Barral.

- (2004). «La poesía puede ser cualquier cosa menos un acto de ingenuidad». El País, 14 de agosto, 2-3.

Heidegger, M. (1980). Arte y poesía. México: Fondo de Cultura Económica.

LYOTARD, J. F. (1984). La condición postmoderna. Madrid: Cátedra.

- (1985). La postmodernidad (explicada a los niños). Barcelona: Gedisa.

RACIONERO, Q. (1998). «No después sino distinto (En torno a un debate sobre ciencia moderna y postmoderna)». http://www.uned.es/dpto fil/seminarios/polemos/.

- (2005). «Sujeto histórico, comunidad política y nihilismo». En Pensar la comunidad, Quintín Racionero y Pablo Perera (eds.), 15-65. Madrid: Dykinson.

Rodríguez García, R. (1994). Heidegger y la crisis de la época moderna. Madrid: Ediciones Pedagógicas.

SCARANo, L. (2004a). Luis García Montero: la escritura como interpelación. Granada: Atrio.

- (2004b). Las palabras preguntan por su casa. La poesía de Luis García Montero. Madrid: Visor Libros.

TAlens, J. (1979). Beckett y su obra. Barcelona: Dopesa.

- (1994). Escritura contra simulacro: el lugar de la literatura en la era electrónica. Valencia: Episteme. Col. Eutopías.

- (2000). El sujeto vacío. Madrid: Catédra. Col. Frónesis.

- (2005). «Contrapolíticas del realismo». En Poesía hispanoamericana contemporánea, Andrés Sánchez Robayna y Jordi Doce (eds.), 129-159. Barcelona: Galaxia Gutenberg / Círculo de Lectores.

VALENTE, J. Á. (1991). La piedra y el centro. Variaciones sobre el pájaro y la red. Barcelona: Tusquets.

Vattimo, G. (1983). Il pensiero debole. Milán: Feltrinelli. 